\title{
WORKING TOGETHER IN CLASS
}

\author{
Marioara PATEȘAN \\ mpatesan@yahoo.com
}

“NICOLAE BĂLCESCU” LAND FORCES ACADEMY, SIBIU, ROMANIA

\begin{abstract}
The scores obtained by the military students are very important as a lot of opportunities depend on them: the choice of the branch, selection for different in and off-campus activities, the appointment to the workplace and so on. A qualifier, regardless of its form of effective expression, can make a difference in a given context of issuing a value judgment, in relation to the student's performance assessment. In our research we tried to find out what motives students, what determines them to get actively involved in the tasks they are given and the ways we can improve their participation in classes and assignments. In order to have an educated generation we need to have not only well prepared teachers but ones that are open-minded, flexible and in pace with the methodological novelties that can improve the teaching learning process in class. Along the years we have noticed that in classes where students constituted a cohesive group with an increasing degree of interaction between members, the results were better than in a group that did not appreciate team-work. In this article we want to highlight the fact that a teacher can bring to class the appropriate methods and procedures can contribute decisively to the strengthening of the group cohesion and high scores.
\end{abstract}

\section{KEYWORDS:}

Teamwork, cooperation, collaboration, interaction

\section{Introduction}

A teacher is considered to have results if his/her students get the desired competences in the subject taught/learnt. In our world, in all fields of activity individuals work together not only to achieve shared goals but also to maximize their own and each other's learning. This interdependence among persons can be of three types: cooperation (positive input and results), competition or individualistic effort. In our case cooperation is the one that made students work together to achieve desired learning goals and complete common specific tasks and assignments. Teamwork develops students' ability to work together and is an important competence for their lives and work of future citizens.

\section{Literature: Cooperation - We Sink or Swim Together \\ We will discuss the two models used} in cooperative learning: the Johnsons' model and the Kagan's one. There are slight differences and many similes between these two models. These two models have common beliefs such as: the importance of 
Positive Interdependence, Individual Accountability, Social Skills Development, and Face-to-Face Interaction and they both try to offer the teachers some answers and procedures that can be applied in class. The Johnsons stressed the importance to work together in their book Active Learning: Cooperation in the College Classroom (Johnson, Johnson \& Smith, 1991) by describing this need quite plastically: We sink or swim together versus We are each in this alone or if we want to compete we choose: I swim, you sink; I sink, you swim. In their view the main objective of group work is to involve learners actively in the learning process when there is a common goal accepted by everyone. They also consider that in a cooperative learning environment, "interaction is characterized by positive interdependence between objective and individual responsibility" (Johnson \& Johnson, 2002). By that time, teamwork had already been in practice for almost 10 years being considered the "most appreciated managerial competence" (Goleman, 1998).

Cooperative learning was used strategically and along the years, research has shown that "cooperation structures are better than competitive ones and based on individualism, both in terms of school and social performance, regardless of content and educational level" (Kagan, Kagan \& Kagan 1997; Kagan, 2001).

The five conditions under which cooperative learning is productive according to the Johnsons' model are as follows:

1. Clearly perceived positive interdependence

2. Considerable face-to-face interaction

3. Clearly perceived individual accountability and personal responsibility to achieve the group's goals

4. Frequent use of the relevant interpersonal and small-group skills

5. Frequent and regular group processing of current functioning to improve the group's future effectiveness

Kagan, on the other hand, considers six keys to be successful in cooperative learning:
1. Effective formation and utilization of teams

2. Development of the will among students to work together

3. Efficient management techniques

4. Development and practice of social skills among students

5. Appropriate implementation of structures

6. Inclusion of four basic principles, symbolized by the acronym PIES in which:

- $\mathrm{P}-$ Positive Interdependence $=$ A gain for one is a benefit for the other

- I - Individual Accountability = Students work together as a team to create and to learn, but ultimately every individual student is responsible for his or her own learning

- $\mathrm{E}-$ Equal Interaction $=$ Students learn by interacting with the content and with fellow students so participation must be relatively equal

- $\mathrm{S}-$ Simultaneous Interaction $=$ Students learn better when a high percentage of them are actively engaged at once (Kagan \& Kagan, 2009, pp.121, 129, 214).

We can notice that the element overlap in these two models, the approach being a bit different. Thus, while the Johnsons believe that "cooperative learning groups have five essential elements (positive interdependence, individual accountability, face-to-face interaction, social skills, and processing) built carefully into every lesson to teach the students to learn well together" and call for teachers to "tailor cooperative learning lessons to meet the unique instructional circumstances and needs of the curricula, subject areas, and students", the Kagans urge the teachers to make cooperative learning part of every lesson by including structures as the goal of the teacher is to become competent in a range of structures, not simply to become competent in planning and delivering 
cooperative learning lessons. They states that once the teacher knows any one structure, the teacher can easily generate an infinite number of activities.

The essence of the Kagan model is Structure + Content $=$ Activity. All these professors offer two sets of criteria: each member has a unique contribution to make as each member must contribute if group is to succeed (Johnsons) and each member's contribution or gain improves the outcomes and help is necessary-all must contribute to achieve success (Kagan, 2001).

At first sight very similar, they differ not only in the terms used, groups versus teams, but mainly in the ways of implementation. Thus, in the Johnson model, the focus is on the lesson being important how the teacher is planning and delivering cooperative learning lessons while the Kagan model considers necessary that teachers are skillful in a range of structures.

Out of the four basic principles of cooperative learning symbolized by the acronym PIES the first two elements Positive Interdependence and Individual Accountability are common to both models. The differences occur in the applying of the last two of the PIES principles, Equal Participation and Simultaneous Interaction. Te question is if there is real equal participation in a group or team activity as students' skills and thus contributions are different. Can a teacher measure each members' contribution? Kagan's answer is no but the teacher can monitor the activity and structure it accordingly to give more equal opportunities for the members by simultaneous interaction, whereas the Johnsons' Learning together model militates for face-to-face interaction.

\section{General strategies in making up teams/groups}

In order to have a successful activity in class the members of the teams/groups should complement their individual skills/ competences. Heterogeneity of a team is a plus value so the members should find out each strengths and weaknesses and use them accordingly. They should cooperate and rely on each other to reach effectiveness. People can be manipulated on the condition to push the right buttons.

When we make up a team we start having in mind the objective to be able to solve the problem: the model may seem simple-to reach the goal the team members should cooperate but as cooperation without collaboration and cooperation do not exist, communication is very important.

The next element we should take into consideration is the size of the teams. We have noticed that a larger number of members -7 for example - versus a team of 3, were more innovative in the solving of the problem as the ideas produced by the members were more numerous.

The complexity of the issue to be solved is also important as a simple one does not necessarily need cooperation between the team members, as it can be solved individually. The more complex a task is, the more incentive is the team work: the students want to prove they are creative, dynamic, eager to be asserted and recognized. The moderator has a very important role as he/she should make sure that the objective is reached, that the members of the group/team are focused on the given task. Victory is very important for the moderators so they have to stimulate the others, adapt the rules for the team so as these should become more efficient in finding the best solutions in the solving of the problem. If the moderators want to be successful they should make sure that they are prepared, that every member is responsible for team progress and team/group success, listen carefully and show respect for contributions of other members, pay attention to inappropriate behavior, criticize ideas not persons, make sure that only one person speaks at a time and everyone participates and no one dominates, carry out the assignments on time and be ready to present the findings as the spokesperson of the team/group. 
By team/group working learning can be improve if they are well planned, guided and closely observed. By asking and answering questions in English they practice their grammar, by formulating ideas or solutions they use their vocabulary, by comparing different issues they make use of previous knowledge. Even when grammar is not properly used neither the vocabulary rich, communication and learning happen. When students work in groups, they have to work together to accomplish an objective.

The steps taken for team/group work are the following:

- Make up the teams/groups;

- Raise a problem or ask an open question;

- Leave students time to think it over;

- Leave them share ideas and discuss the solution/answer;

- Let them share their solution/ answer with the other teams/groups;

- Let them comment on the answer/ solution found by the teams and come up with one valid solution/answer;

- Appreciate their work.

\section{Possible practical activities}

Team/ group work or collaborative learning can take different forms, such as quick activities in class or more involved group projects that cover the course of a semester. For quick activities we can suggest an introducing activity at the very beginning of a semester when the teacher and students do not know each other. The teacher tells the students to mingle and by asking questions in English about the place of birth, residence location, former studies, family, likes and dislikes, etc. to be able to introduce one or two fellow students. The teacher will assess their grammar, vocabulary and speaking skills. This type of collaborative activity encourages speaking and listening as students feel more confident with their partners.

If for the quick activities in class we can choose a range of questions or situations that need a short period of time to be solved for the group projects we need to plan it thoroughly. We use the group projects more often as the number of classes at our disposal is limited. We introduce the group project early in the semester so the students can manage the time needed. Then we explain our students how groups will operate and how they will be graded. The groups projects are more elaborative and need more time. The groups are larger and their members can be nominated by the teacher or at the students' free choice. They can practice being the speaker, the note taker, the researcher or chair person by taking turn. They should act as a team and divide the tasks and organize themselves. Working on sharing tasks encourage the students to find to retrieve and synthesize new information, to use the language in presenting facts, making suggesting, justifying opinions as well as developing of reading comprehension, listening and speaking skills.

It is important that the teacher should assign tasks that match the learning objectives of the course and mention from the very beginning the way of evaluation for each and every member of the group. No matter who the chair person is, the assessment of the project is given not only by the presentation of the findings but also by the final outcome as such. This way each and every member of the team/group knows that his or her involvement in the project is important as it matters for the final result that is concluded in a score. The teacher lets the students know that he/she is not interested that only a few might have done all the work and everyone gets the same grade as they should solve it by themselves within the team/group. For example if we ask the students to bring in information for each course they have during a semester by letting them know the tasks from the very beginning of the course we involve them as they can generate course content and present it to their colleagues. If each group/team knows from the very beginning 
the task they can manage the time, organize themselves in using course content or other academic sources to reach the goal and be successful in their endeavor.

We prefer group projects as they can reinforce skills that are relevant to both group and individual work, and as the National Survey of Students Engagement of 2006 found out, it also includes the ability to:

- to break complex tasks into parts and steps;

- to plan and manage time;

- to refine understanding through discussion and explanation;

- to give and receive feedback on performance;

- to challenge assumptions;

- to develop stronger communication skills.

In asking the tasks of a team/group project the students develop skills necessary in their future profession as well such as: the ability to deal with complex problems, assume roles and responsibilities, improve knowledge and skills, hold their partners responsible and accountable for their part in the project, find new approaches to deal with new issues, develop their own voice in relation with others, communicate better, appreciate work as a team.

Over the years we have noticed that cooperative-learning brought along an increase in engagement and active participation in the learning process of the students. They solve the tasks at their own pace being under no stress, feeling among 'friends' and not under the lens of the teacher. The group project should be seen as an instructional and learning opportunity at the same time.

\section{Conclusion}

Although group/team work needs preparation and planning, clear explanations how groups should operate and how they will be graded, the teachers should include this technique during their courses/classes as we noticed that it can be beneficial for students. The learners can explore and notice their own improvement within a friendly environment. It is important that groups function well as students should accomplish their individual responsibilities within the group. Being supportive with each other, interactive well and prepare their share of the task on time leads to the cohesion of the team/group and to god results as well. Group work helps students learn how to work with people having different backgrounds or experiences. As Johnson determined, students learning in a collaborative situation got greater knowledge acquisition, retention of material, and higher-order problem solving and reasoning abilities than students working alone (Johnson \& Gonzalez, 2014). If the team/group works effectively the students can deepen their understanding of a particular subject, develop interpersonal skills such as speaking and listening as well as working skills so necessary in their future profession, namely leadership, working with and motivating others, identifying your own and other's strengths and weaknesses. Productive group work is that one in which all students contribute where the learning and learners are interdependent. 


\section{REFERENCES}

Goleman, D. (1998). Working with emotional intelligence, New York: Bantam.

Johnson, C., \& Gonzalez, A. J. (2014). Learning Collaborative Team Behavior from Observation, Expert Systems with Applications, 41(5), 2316-2328.

Johnson, D. W., Johnson, R. T., \& Smith, K. (1991). Active Learning: Cooperation in the College Classroom, Edina, MN.: Interaction Book Company, 37.

Johnson, R.T., \& Johnson, D.W. (2002). An Overview of Cooperative Learning, available at: http://digsys.upc.es/ed/general/Gasteiz/docs_ac/Johnson_Overview_of Cooperative Learning.pdf.

Kagan, L., Kagan, M., \& Kagan, S. (1997). Cooperative Structures for Teambuildin, San Clemente, CA: Kagan Publishing.

Kagan, S. (2001). Structures and Learning Together: What is the Difference?, San Clemente, CA: Kagan Publishing, available at: https://www.kaganonline.com/ free articles/dr_spencer_kagan/275/Kagan-Structures-and-Learning-Together-What-is-theDifference

Kagan, S., \& Kagan, M. (2009). Cooperative learning, San Clemente, CA: Kagan Publishing.

National Survey of Student Engagement. (2006). Engaged Learning: Fostering Success for All Students - Annual_Report 2006, available at: https://archive.org/stream/ERIC ED512619\#page/n0/mode/2up 